\section{Reflection and Metacognition in Mathematics Education - Tools for the Improvement of Teaching Quality}

\author{
Christa Kaune, University of Osnabrück \\ (Germany)
}

\begin{abstract}
On the basis of a category system that classifies metacognitive activities, the first part of this paper shows to what extent reflection can be understood as one of several metacognitive activities. It is then demonstrated that it proved to be useful to consider different nuances of reflection.

Illustrated by examples taken from math classes on grammar school level, the second part of the essay shows what assignments look like that cause pupils to reflect, and how pupils face up to the demands to reflect on different matters in mathematics education.
\end{abstract}

\section{ZDM-Classification: D43, E44, E53, H33}

\section{Reflection, understood as a metacog- nitive activity}

The demand to cover central ideas concerning mathematics education in a challenging and thorough way, and to stimulate pupils' thinking processes about mathematical matters, has been present in math didactics literature throughout the last two decades. Thereby, the term "reflection” is frequently used. Kilpatrick (1986, p. 8) describes how the connotation of this term, originally used to depict physical and geometric phenomena, changed and now serves as a metaphor for a variety of cognitive processes.

Sjuts (1999a, p. 40) specifies "reflection" as "comparing and scrutinising cogitation, thinking, and examination, directed to the matter at hand, which is characterised through differentiation, detachment, and deepening." One can find other descriptions like "to engage in soulsearching", "to pass in revue", as well as "to relate things". Thus, "reflection" is used to describe a particular kind of high-level cognitive thinking process. The main lecture of Kilpatrick at ICME5 (Kilpatrick 1986) is considered trendsetting in the international discussion about making reflection a central part of mathematics education. Also, in his studies on a reform of mathematics education on late high school and undergraduate level in the USA, Dubinsky (1991a, b) emphasises the usefulness of reflection for an understanding of mathematics. By saying

„... that we somehow move into another dimension when we reflect on what we have done."

Kilpatrick (1986, p. 9) indicates that reflection is done from a superordinate point of view and that activities on the object level are viewed from a meta-perspective.

Since the 1970s, the term "metacognition" has been established in cognitive psychology for this kind of cognitive activities (cp. Boekaerts 1996). The prefix "meta" suggests that internal processes are central to this concept.

Wang, Haertel \& Walberg (1993, p. 272f) emphasise the relevance of metacognition for learning achievements in general. In their metaanalysis of empirical studies on the success of school learning, they observe that metacognition is in an excellent rank regarding the influence on learning achievements. Schoenfeld (1992) and De Corte (1995) report on the importance of metacognitive activities to improve mathematical thinking and learning processes.

Konrad (2005, p. 23) and Sjuts (1999a, p. 40-44) differentiate the terms "cognition" and "metacognition" from one another. However, Flawell (1979) shows on the one hand that "reflection" is not used consistently in everyday speech, and on the other hand his examples also indicate that both concepts are not clearly differentiable in everyday situations.

Sjuts (1999b) characterised different metacognitive activities and documented their relevance to explain pupils' achievements. By means of transcript passages and pupils' solutions, the mechanism of action will be demonstrated, with a particular focus on the question, which metacognitive activities bear on which cognitive processes.

\section{Category system to classify metacogni- tive activities}

\subsection{Formation of a category system}

From 2001 to 2004 a project supported by the "Deutsche Forschungsgemeinschaft" (German Research Foundation), subtitled "Analysis of 
educational situations practicing reflection and metacognition in secondary school mathematics education" was conducted at the "Institut für kognitive Mathematik" (IKM) (Institute for Cognitive Mathematics) of the University of Osnabrück. The title already indicates the connection between metacognition and reflection.

In the present project ${ }^{1}$, the construct "metacognition" was decomposed under mathematics didactical aspects. Single activities were identified and used to build an extensive category system for metacognitive activities that were observed in teacher-pupil interactions in mathematics education. This system was then applied to some transcript passages. The analysis emanated from algebra lessons. In the process of the category formation, however, it became apparent that the observed and identified activities are also describable in a more general way. Consequently, the category system can more generally be applied so that it can now subsume metamathematical activities as well (cp. Cohors-Fresenborg \& Kaune 2005a).

This at first astonishing connection between metamathematics and metacognition can therefore be explained. In the context of an education according to the "Osnabrücker Curriculum" (Curriculum of Osnabrueck, Cohors-Fresenborg, 2001), an incentive could be to transform cognition, through metamathematical approaches, into a metacognition on mathematical prodedures ${ }^{2}$.

The importance of metacognition for the comprehension of mathematics is revealed by another observation: In mathematical science, the thinking about the nature of mathematical conceptions and the typical procedures that are used when practising mathematics (calculating, proving, abstracting, reifying) lead to the classical main components of metamathematics (mathe-

\footnotetext{
1 Supported by the German Research Foundation under reference Co 96/5-1. In German-speaking countries, this project is the first and so far only project that intensely investigates the role of metacognition in mathematics education. All the examples mentioned in the present study were analysed within this project.

${ }^{2}$ Examples are the scene of the lesson on the barrel rule at the end of this paper as well as the episodes "Proving is nothing else but calculating" (CohorsFresenborg \& Kaune 2005b) and "Do we need a $4^{\text {th }}$ binomial formula?” in Kaune (2001).
}

matical logic): computability theory, formal logic, axiomatic set theory.

\subsection{Application of the category system to the analysis of scenes of lessons}

A scene of a lesson on "equation-solving" is chosen to illustrate to what extend the processes "reflection" and "metacognition" interact. It also shows which criteria are suitable to differentiate reflection from other metacognitive activities. Transcripts and pupils' solutions that are analysed in the following are part of the mathematics educational databank MUMAS ${ }^{3}$.

\section{Initial setting of the scene ${ }^{4}$ :}

The pupil Michaela stands in front of the blackboard which contains the equation $0, \overline{6} \cdot(x-5)-\frac{2}{3} \cdot(11-2 x)=1+x$ that is supposed to be solved. Michaela moderates the procedure; she calls up pupils, who are allowed to dictate one term rewriting only and she writes as they dictate. It is part of the classroom-culture that the pupil standing at the blackboard is not supposed to control the inputs given by the class concerning their completeness and correctness. Also, he or she is not allowed to change the contents of what is dictated.

\section{Transcript ${ }^{5}$ :}

\section{2}

Rainer: Yeah, well, first I'd turn the $0, \overline{6}$ into $\frac{2}{3}$, because then it is a little more consistent.

[Michaela draws an equivalence sign and writes the

4 fraction $\frac{2}{3}$ below the $0, \overline{6}$. She then turns to Rainer.]

6 Michaela: It's not done yet, is it?

Rainer: And now, of course, write down the rest again. And, well, you could of course directly apply the distributive law, too, hum, write it in

10 front, then you'd have to put two hum thirds times $\mathrm{x}$ hum minus two-thirds times five hum

12 minus two-thirds times eleven minus two-thirds times two $\mathrm{x}$ equals one plus $\mathrm{x}$.

14 [Michaela writes down what Rainer dictates. Noisy agitation in class. Clearly visible in the video:

16 Moni turns to her neighbour Elfi, talks to her,

\footnotetext{
${ }^{3}$ MUMAS: MUltimedia-based Mathematics didactical Analysis System, presented for example in Kaune (2005).

${ }^{4}$ MUMAS-scene 254_01

${ }^{5}$ Only the coloured text passages of this transcript are analysed in this paper.
} 
and shows up at the same time.]

18

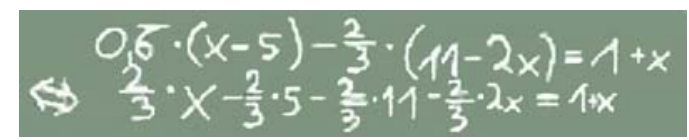

Michaela: Moni

20 Moni: I think, (...) in the second row it doesn't work out completely, namely at the second time twothirds, the algebraic sign shows up for the second time in front of the number and in front of the two-thirds there's a negative sign, hum, after the first parenthesis, thus, negative two-thirds and if you then...

[While Moni speaks, Michaela already changes the minus in front of the term $\frac{2}{3} \cdot 2 x$ into a plus.]

... apply it with the distributive law and then you should, it should be: well, $-\frac{2}{3} \cdot 11$ and then, and then, hum, Rainer did, did dictate "plus" but then there would have to be a negative sign again in front of the two-thirds.

34 Michaela: Yes, I just put it there.

Moni: Yeah, but hold on a second. Oh, I see,

36 Michaela already put it there. Yeah, it works, now.

38 Rainer: So, did I make a mistake?

T.: Rainer just asks if he made a mistake. Can we look for that on the right hand side and check it again on the blackboard?

42 Rainer: I didn't get it yet, the whole thing.

The mistake is clarified on the object level. In particular, the pupils explain the substitution of the variables when applying the distributive law.

Rainer: Well, now, I've made that mistake quite often. I overlooked that minus, after the, hum, after the $x-5$-parenthesis, because, hum, I just had the idea in my head that I always, well, at the first term in front of the equals sign, hum, I divided it into two parts, $0, \overline{6} \cdot(x-5)$ is the first part and the other part was $\frac{2}{3} \cdot(11-2 x)$. And in between hum I have the minus, which means that I somehow always have to subtract the second part from the first. That's how it looked like in my head. And that was the mistake.

Sven: Well, hum, I wanted to add something to what Rainer just said, that he makes mistakes with things like that, well, hum, when I do these assignments at home or so, and they are hum a little longer and contain things like this minus, then I underline those parts most of the time. Well, hum, that way I see that there is a negative sign in front and that you have to take it into account later, when you apply the distributive law. Yeah, this way it works pretty well, if you keep it in mind all the time.

\section{Interpretation:}

An analysis of the preceding lines uncovers different discursive ${ }^{6}$ and metacognitive activities of the participants:

Moni not only criticises a classmate's mistake "in the second row it doesn't work out completely" (line 20f), but she demonstrates her awareness of mathematical methods: she observed an incorrect application of the distributive law (line 29). This is a specification of monitoring, one category of the category system "Metacognitive activities at calculating and proving” (Cohors-Fresenborg \& Kaune 2005a), that is used to classify metacognitive activities in mathematics education at the IKM. As a reflecting judgement and evaluation of the procedure, her later utterance (line 36f) "...it works now" belongs to a second category, called reflection. Rainer's positioning “I didn't get it yet, the whole thing" (line 42f) falls in another subcategory of monitoring. The same holds for his way to address his wrong conceptions (lines 43-53) after the mistake had been discussed on the object level. It is evident that he wonders by himself to what extend concrete mistakes can be explained as results of generally wrong conceptions. It can be assumed that an interplay in the following sense is taking place: Since Rainer addresses his wrong conceptions, Sven, in his explanation, feels obliged to refer to his conceptions and the related metacognitive procedures. Michaela's activity has to be evaluated differently: During the calculation, she monitors her classmates' contributions "It's not done yet, is it?” (line 6). She already corrects the mistake before Moni finishes her sentence (line 27f). This accompanying monitoring, the ongoing control of what is written or said, and its correction if needed, falls in another subcategory of monitoring.

Rainer's utterance (line 1) comprises a completely different metacognitive activity: he expresses in advance, before dictating a term rewriting, a next step in the calculation: "first I'd". He also explains this step: "because then it is a little more consistent". Thereby, he refers to a consistent notation of the numbers. The action of expressing the next step of a calculation or a strategy in advance, as observed here in the local

\footnotetext{
${ }^{6}$ A deeper analysis of transcripts of this lesson under the perspectives "discursive classroom-culture" and "cognitive structures of pupils" can be found in Cohors-Fresenborg \& Kaune (2003).
} 
justification that produces an advantage in the calculation, falls in the category of planning. The teacher's impulse to organise a controlling "check it again on the blackboard" (line 40f) - is associated with the same category, but a different subcategory.

In his contribution to the discussion, Sven shows discursive qualities as well as metacognitive activities that are evaluated differently: In lines 5557, he explains to his classmates how he organises his controlling at home. In line $57 \mathrm{f}$ he reports on a deliberately chosen display format, a deliberate marking of certain parts of the equation "I underline those parts most of the time". Finally, he evaluates his procedure "this way it works pretty well". This involves the reflection on a planned measure of monitoring.

The three activities planning, monitoring, and reflection are main categories - containing several subcategories each - of a larger category system that includes metacognitive activities of learners and teachers.

At first glance, the activities "planning”, "monitoring" and "reflection" are clearly differentiated. Planning is targeted at the future, monitoring is „online“ in the process of a mental activity, reflection deals with an activity with hindsight, after it has been completed. Obviously, the reference to time serves as a differentiator for these metacognitive activities. However, on closer examination, planning or monitoring processes can also be subject to analysis, monitoring processes can be planned, maybe planned measures can also be designated for reflection. Even a monitoring of reflection and planning processes is thinkable. This analysis shows that the activities "planning", "monitoring”, "reflection" need to be differentiated relative to each other. Also, the differentiation by time that was mentioned is not an absolute one, but merely relative. This can be well observed in the analysis of lines 55-63.

We are here dealing with a phenomenon that is not untypical in mathematics: Processes on one level can become the objects of a superordinate level. In mathematics, we are used to the idea that functions themselves, understood as objects, can become the argument of other functions (for example when differentiating or integrating).

All parts of the preceding transcript that are associated with one of the categories are marked with different colours. A classifying statement of the teacher was additionally underlined for better accentuation. See Cohors-Fresenborg \& Kaune (2005a) for information concerning the procedure of constructing the category system and its exemplary application on further lessons.

The pupils' metacognitive activities documented in the transcript reflect the results of measures persistently taken in the special mathematics education during one school year. The probability of students acting the way we observed in the transcript was raised by theses measures.

One of these measures is displayed in the modified role of the teacher: proposals to improve mathematics education (Bundesministerium für Bildung und Forschung [German Federal Ministry of education and research], 2001, p. 49) emphasize that math teachers should ideally take the role of a mediator that does not "feed" information to the pupils, but that offers opportunities to develop and exchange their own thoughts. As a mediator, the teacher places pupils' ideas into the context of the lesson, relates the uttered thoughts to one another, and supports pupils in the formulation and realization of ideas. While these goals are expressed as goals for the behaviour of the teacher, individual pupils of this class already express some of those behavioural patterns and activities.

\section{Further occasions for reflection}

Since working on assignments is by far the most important activity of pupils in math lessons, it is obvious and often postulated by didacts to use the assignments as a starting point to improve the quality of instructions.

Pupils will only change their focus of attention in class
if it becomes less important for written tests to exclu-
sively learn the formulas written on the blackboard. In
order to achieve comprehending learning, a reorienta-
tion of education needs to be expressed simultane-
ously in tests by a rebalancing of "calculating-
assignments" and "thinking-assignments". (Bundes-
ministerium für Bildung und Forschung [German Fed-
eral Ministry of education and research] 2001, p. 90)

So, how do these special assignment-types stimulating metacognitive activities and especially reflection look like?

\subsection{Reflection on calculation steps and on the adequacy of a method used}

In 1997, in the recommendations concerning curriculum design and further education of 
teachers, the $\mathrm{MNU}^{7}$ demanded the "presentation and reflection of different ways to find solutions" for mathematics education on nongrammar secondary-school level ${ }^{8}$. This includes a special kind of cognitive thinking process while working on an own solution, as well as a comparison of different ways to come to a solution. Sjuts (1999b) used the example of equation-solving-assignments to describe a method that supports monitoring as well as reflection: While dissolving an equation, pupils explain their procedure in a second column. For each step, they write down the abbreviations for the theorem, definition, or axiom. This is a comment on a meta-level.

The following example ${ }^{9}$ is taken from a written test of a class that was instructed according to the "Osnabrücker Curriculum" (curriculum of Osnabrück) (Cohors-Fresenborg 2001) in the third year. It demonstrates the way in which pupils, after having simplified algebraic root-terms, are stimulated to account for the methods they used. Pupils dispose of mathematical objects with the help of names. But the question, if the used symbols are truly names for existing objects or just meaningless words is not answered until some calculation steps are done.

\section{Problem:}

Four pupils are discussing the solution of the following problem:

Simplify the following term if possible:

$$
\sqrt{\sqrt{18}-4,5} \cdot \sqrt{\sqrt{18}+4,5} \text {. }
$$

Silke: "First I thought, the result would not work. But now, I know, it has to be $-\sqrt{2,25}$ and that is $-1,5$."

Eva: "That is not possible, because the solution is syntactically wrong."

Michaela: "Not only the solution, but also the first line must be wrong."

Ariane: "Every line is wrong. I think we should not even have started calculating ... “

a) Which of Silke's comments do you agree with?

b) Why does Eva think that the solution is syntactically wrong?

c) Do you agree with Michaela?

d) Please evaluate Ariane's comment.

\footnotetext{
${ }^{7}$ MNU: association of teachers for mathematics and natural sciences

${ }^{8}$ http://home.zugang.net/mnu-sachsen/sek1.htm, [17.3.2006]

9 MUMAS-scene 54_01
}

\section{Analysis of the problem}

Silke's comments in problem part ,a' reveal pupils' attitudes which can be described as the careless manipulation of terms. They do not consider any underlying basic rules. They adjust parts of the term in a way that favours further processing.

A mixture of correct and incorrect calculations, inadequate attitudes as well as misconceptions of pupils is presented in terms of a fictive dialogue. In the problem, the pupils discuss the non-observance of the domain of the root function and the meaning of term-equalities. In order not to make the problem obvious at first glance, a difference was inserted in the root function while constructing the term. The inner term does describe the name of a number; however, it does not belong to the domain of the outer root function.

This problem belongs to the type „Take up a position!“ The design principles and intended effects of such problems are described in Kaune (2001, p. 44). This type of problem encourages pupils to exercise the metacognitive activity "Reflection" that Kilpatrick (1986, p. 8) describes as follows:

Nonetheless, the image of reflecting on an idea, turning it over in one's mind, is a powerful device for thinking about thinking, and for thinking about one's own thought.

Linguistically and logically complex, Silke's comments decompose into different parts: If "This doesn't work" is interpreted such that a term rewriting is not possible, one can agree with her first sentence. A separate calculation of $(\sqrt{18}-4,5) \cdot(\sqrt{18}+4,5)$ results in $-2,25$. The number $-\sqrt{2,25}$ is correctly shown without root. The design of Silke's second sentence only permits to agree with the last term equality.

Part ,b' serves to focus the pupils to the problem of sense-emptiness of certain formal written figures. The word choice of the fictive pupil Eva is intended to show that the pupils also know how to differentiate between incorrect semantics and syntax, when working on the problem.

Problem parts ,c' and ,d' are meant to teach the pupils to reflect more precisely about the significance of term rewriting. Also, they must exactly localize where the problem first occurs. 
Interpretation of a pupil's solution Marion's ${ }^{10}$ solution to ,a':
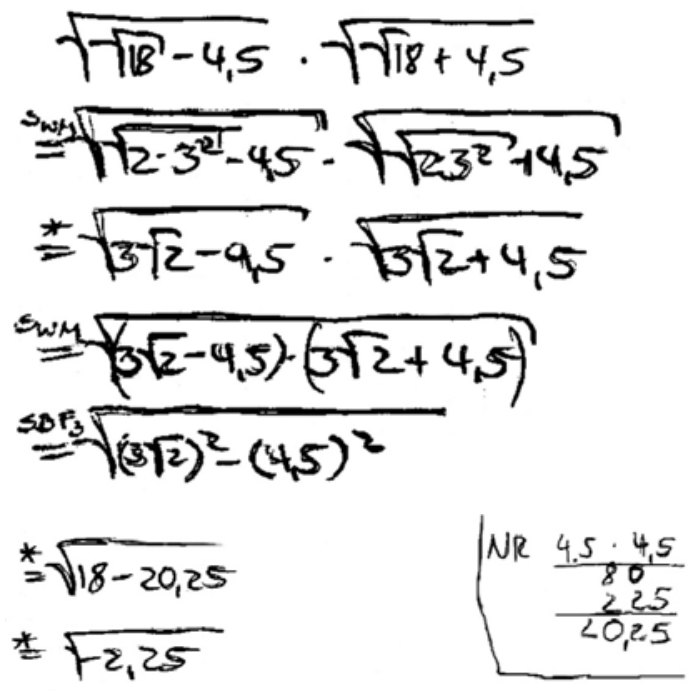

Marion's answer to question a:

Silke's first assumption is correct since $\sqrt{-2,25}$ is not the name of a number. There is no number that results in $-2,25$ when multiplied with itself.

You are not allowed to simply write the algebraic sign in front of the square root symbol.

Marion's term rewritings clearly show methodical procedures which support the monitoring of term rewritings. In class, it has been established to specify names above the equals signs to indicate the basic logical rule used for this calculating step (e.g. * is the name for a term replacement rule) or the proved theorems $\left(\mathrm{SBF}_{3}\right.$ stands for the third binomial formula, SWM for a theorem that regulates the multiplication of numbers of a square root). As the concrete formulation of the problem does not explicitly demand this procedure, it is evident that it has become a component of the pupil's "cognitive operating system". All of her term rewritings refer to the inner functional term. They have been carried out according to the rules, in case they were applicable.

Marion formulates a differentiated answer to Silke's statement: She agrees with the first part and supports this by an explanation that indicates that she knows the definition of a number in root notation She interprets the appearance of the term $-\sqrt{2,25}$ as a careless use of the algebraic sign ("You are not allowed to simply ..."), i.e. as a term rewriting that is not justified by a

\footnotetext{
${ }^{10}$ Analyses of other pupils' solutions of these parts of problem can be found in Cohors-Fresenborg \& Kaune (2005b).
}

suitable rule. Here she practices reflection as described by Kilpatrick (1986) on page 8 .

It is not surprising that, after having handled part ,a' of the task, she appropriately solves parts ,b' and ,c':

The first line and the one in between have to be incorrect, too, because we always concluded something starting at the first line and there are equals signs and every line is explained by a paragraph.

It is striking that she does not use the word "name of a number" anymore - as she did in problem part a. Instead, she calls the written figure "line". The equals signs explained by paragraphs convey a feeling of correctness to her. She is assured that she did not do any mistakes in the single calculation steps.

It would have been desirable for her to legitimate her calculation "subject to changes" in the beginning. She expresses in her comments to ' $b$ ' and ' $c$ ' that there is no true mathematical term in any of her calculating lines. A clarification is not given until she comments part ,d':

You are allowed to start calculating, because it cannot be seen immediately that the term is syntactically wrong. This is not possible until you finish calculating.

The availability of Computer Algebra Systems (CAS) can provide new occasions for a reflection on the results of the used tool. This can be seen in the following problem ${ }^{11}$ from an examination in $11^{\text {th }}$ grade. Pupils seem to reflect on an output of a CAS, but really they reflect on their understanding of recursive or inductive definitions.

\section{Assignment:}

To define the sequence $\mathrm{u}_{1}$ with $u_{1}(n)=10^{-(n-1)}$ recursively, Marc enters the following lines into his CAS:

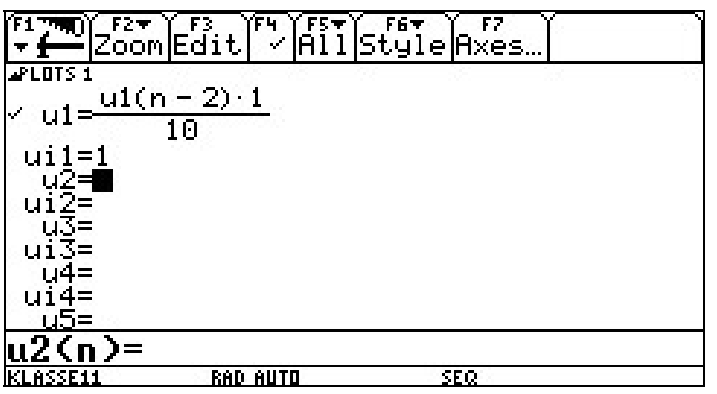

The following error message is displayed as he wants to draw the graph of the sequence:

${ }^{11}$ MUMAS-scene 652_03 


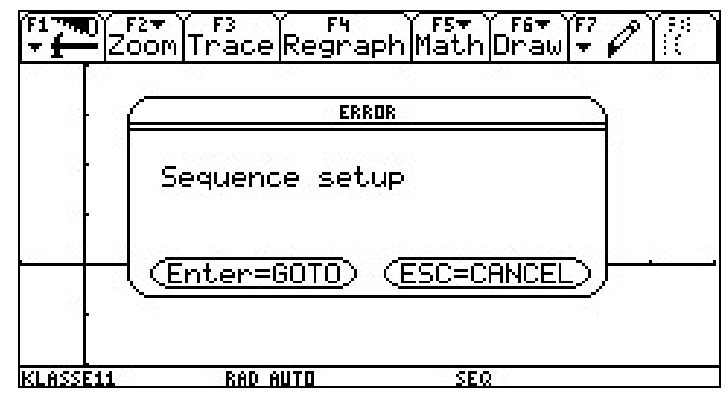

After he deleted the error message, the following graph appears:

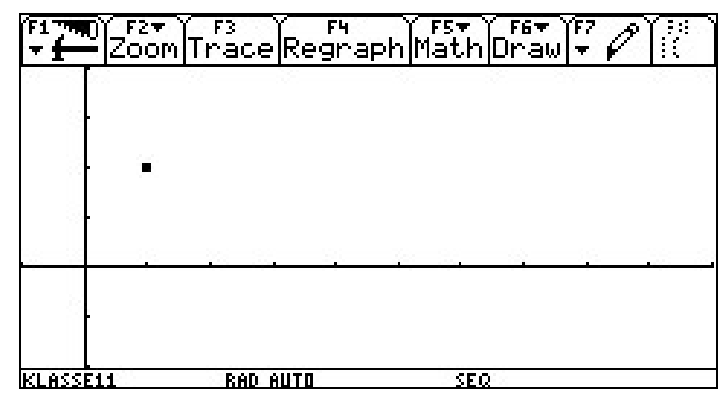

a) Calculate $\mathrm{u}_{1}(2)$ by means of both, the definition given in the display and the explicit definition.

b) Explain why the CAS displays an error message.

c) Explain why the graph consists of one dot only. State its coordinates.

\section{Starting Position and Analysis of the Problem} In this learning group, where every pupil was familiar with the use of a CAS, the CAS was used to "convey a well-balanced image of mathematics and not only to practice to handle mathematics.“ (Herget 1991, p. 147).

The first display shows a definition of a sequence in CAS-notation that corresponds to

$$
\bigwedge_{\substack{n \in \mathrm{N} \\ \wedge}}\left(u_{1}(n)=u_{1}(n-2) \cdot 10^{-1} \wedge u_{1}(1)=1\right)
$$

The sequence only provides sequence members for odd arguments. Thus, it only corresponds to the explicitly defined sequence for a subset of the domain. If you try to inductively determine further sequence members starting from $u_{1}(1)$, such as $u_{1}(2)$ for example, it fails. This also becomes clear through the error message "sequence setup", as shown by the second display, and through the graph of the sequence, which only contains the point $P(1 \mid 1)$ in the third display. Problem part ,a' focuses the pupils on that problem in several steps: The determination of $u_{1}(2)$ on the basis of the explicit definition was not meant to check whether they could calculate terms. It was supposed to test if an adequate comprehension of the concept "explicit definition" was existent. The calculation of the function term could be assigned to the CAS.

However, if you read the definition recursively and ask, for example, for the sequence member $u_{1}(3)$, this can be calculated with the help of the definition by going back to $u_{1}(1)$. This holds for all other odd arguments as well.

In order to "enforce" an examination of the types of definition of $u_{1}$, the scale of the coordinate system in the third display was not chosen equidistant. Consequently, a pupil's solution to problem part ,c' reveals, if the coordinates of a point have simply been read - under the assumption of standard settings of the display - or, if a relationship between definition and graph could be established.

\section{Interpretation of a pupil's solution}

Vera's work on problem part ,a' shows that she can both, explicitly and recursively calculate sequence members:
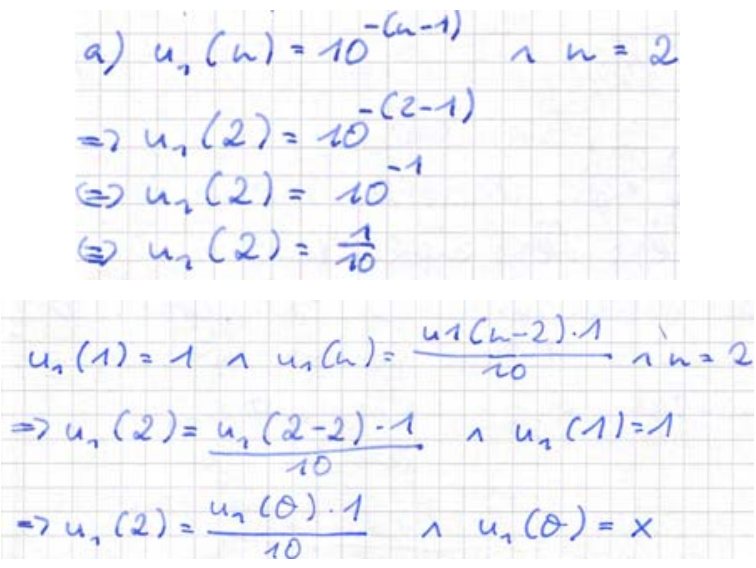

She does not use the $x$ as a name for $u_{1}(0)$, as can be seen in her solution to problem part ,b'. Here, it rather has to be interpreted as something unknown:

The CAS probably displays an error message because you don't know what $\mathrm{u}_{1}(2-2)$ is. This would actually be called $\mathrm{u}_{1}(0)$, but before, only $\mathrm{u}_{1}(1)$ was stated."

She can specify the coordinates of the point in problem part ,c' without mistake.

\subsection{Reflection on the relevance of a concept in the mathematical system of concepts}

Cohors-Fresenborg \& Kaune (2005b) analyzed a scene of a lesson that was based on a discussion 
about the question „Is there a difference between proving and calculating?" At first glance, it is hard to understand why this question is at all asked, because obviously nobody associates "calculating" with the word "proving". The analysis of the pupils' discussion reveals a special point of view, whereby the pupils consider calculating as a progressive term rewriting based on rules. From a cognitive point of view, they have experienced algebraic proofs as a similar procedure. In the course of their reflection on both concepts, the pupils discover themselves that the use of the word „calculating” also involves term rewritings without variables. On the other hand, with the word "proving", they associate the occurrence of variables in terms.

Here and also in the following, possibilities of reflection in mathematics education and the conditions and possibilities for them to become effective, are only taken into consideration on the basis of German mathematics education on grammar school level. It is specific for this kind of education that pupils gain an understanding of the typically mathematical conception and precision process. This process is based on an axiomatic understanding of concepts with appropriate definition and proof concepts. In addition, the understanding of the processes by which such specifications come about, the handling of usual techniques to use the concept of a function and the well-founded handling of equation systems are supposed to be learnt by the pupils.

The following scene of a lesson is taken from an intensive math course with increased demands after the following problem had been worked on:

How much fits into the barrel?

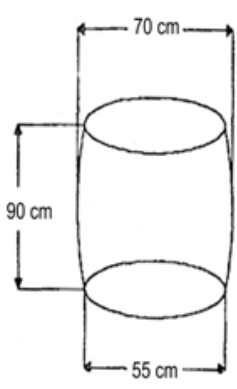

a) Show that the volume is at any rate smaller than $400,000 \mathrm{~cm}^{3}$.

b)Outline a deduction of the formula to calculate the rotational volume

$V=\pi \cdot \int_{a}^{b}[f(x)]^{2} d x$

c) Compute the volume of the barrel as exact as possible.

A group of didacts formulated this problem as an example for a divergent problem format. It already prompted reflection in its developing phase, however, not for the pupils working on it, but for those that formulated the problem as Kind (1994, p. 62) puts it: "The plurality is a guarantor for an intensive reflection on formulations and other possible solutions." Only the following request during the lesson ${ }^{12}$, which was added to the original setting of the problem, challenged to reflect on the nature of mathematical concepts:

$$
\begin{aligned}
& \text { T: Part b of the problem asked: "Outline a deduction } \\
& \text { of the ,formula“ to calculate the rotational vol- } \\
& \text { ume.” We have reflected a lot on these mathe- } \\
& \text { matical concept systems (...), but we hardly } \\
& \text { used the notion „formula”. }
\end{aligned}
$$

Every pupil on high school level has got a formulary. It contains, amongst other things, axioms, interpreted axiom systems, definitions and theorems. However, the concept "formula" is mostly not used in a reflected manner. The use of the word „formulary“ alone does not contribute to solve the problem that was raised. Generally, formulas are (syntactic) written figures which can be deduced from a given formula calculus. In the given problem, the concept "formula" is used in the sense of an equation that only permits numbers, variables and functional signs. The case at hand gives a meaning to the concept "Volume of a rotational body during rotation around the argument axis“, i.e. the concept is defined. The "binomial formulas", however, which are well-known to the pupils, are considered mathematical theorems.

The concepts mentioned by the teacher in line 7 (,the concepts we used”) are obviously concepts such as "theorem”, "definition”, “axiom" or "fundamental term".

8 Anne: Well, I would say, in this case you could maybe use the concept „definition“ instead of „formula“.

We didn’t call this „theorem“, I think somebody mentioned this before, but actually this is a definition, because we stipulated that this is the case and that this cannot be proved now or (...) and therefore I would say you can also ... (...).

16 Else: Oh yes, this can be proved!

T: Please, let her finish her sentence. Yes, Kira?

18 Kira: Yes, actually I would say this is a theorem because it is a .... we had .... well .... It is not a

20 definition.

$\mathrm{T}$ : Jochen!

${ }^{12}$ MUMAS-scene 012_02 
22 Jochen: Yes, at least we derived it from other, hum, areas, equations, hum, from integral calculus for example, and, hum, therefore you cannot really call it, I would say, not really call it definition, as a definition .... It could be said, yes with this equation it can be said, yes, according to what we know, it can be deduced from what we have had before, which means you can .... In any case, it turned out quite reasonably; the definition actually describes something new. And this is actually not really something new, it has only been, yes, found out from other areas, so to speak.

T: Else!

36 Else: Well, I would anyhow say this is a definition in so far as it is about a volume of a rotational body, and we defined this with the help of, yes, other concepts or, yes, in this case it is the integral that helped to describe the volume of the rotational body or, yes, we defined it. The point is: The definition that now introduces such a new concept, with, and explains it with old concepts, which means with concepts already known.

(16 seconds)

At this stage, the teacher is content with the role of a moderator: she calls up single pupils without giving own factual comments. Obviously, her intention is that the pupils develop the comprehension of the concept "formula" together.

In Anne's and Else's opinion, a formula is a definition, because it is a stipulation: „... we stipulated that this is the case" (line 13). An unknown concept is given a meaning by something already known (lines 42-45). In Jochen's opinion, however, the deduction of the formula from something known is a characteristic for the fact that it is not a definition.

At this stage - after an interval of 20 seconds Maret introduces a completely different train of thoughts by explaining her point of view on the concept "volume" as a fundamental term. This gives rise to a spontaneous dialogue with Else who feels challenged to defend her point of view:

46 Maret: But isn't that, isn't that a bit stupid, to simply say that this is a definition, because a volume,

48 for me that is still something like a fundamental term which ..., which you cannot just, ... it is

50 like a Lego brick, it does exist and it is, I don't know..

52 It is certainly not a definition, because then you'd stipulate - I'll call this a rotational body now and I'll explain it that way.

Just as I say: this is a pencil case, it could also be a banana, if I said: „This is a banana”. And volume, that is the fundamental term, somehow,
58 that, that, I cannot deduce it any more in a different way, from other deviations.

60 Else: Not volume as such. But volume of a rotational body. That's what it's about. It is no

62 longer some arbitrary volume.

Maret: Yes. But then it is more a definition of rotational body than that of a volume, which means (...).

66 Else: Yes, yes. And I, hum. If you have a definition, then it is the case that you define this word - if you like, here it is 'volume of a rotational body', you define it using other already defined concepts and that, for example, would be the concept "volume".

72 You would use this concept, that is, one that has hopefully been defined before. And you would have to use it somehow (actually in that way).

Maret presumably imagines a heuristic volume that she describes pictorially by means of a Lego brick, which is simply there, and that she differentiates clearly from the naming of things by means of a definition. In her opinion, fundamental terms are simply there and cannot be explained by other concepts. In her reply, Else clearly differentiates „Volume of a rotational body“, a concept that needs to be defined (which is possibly done with the formula), from the fundamental term "volume". One can infer from her comment that she agrees with Maret that „volume“ cannot be explained more precisely, but that she considers the case "volume of a rotational body" differently. Maret's answer to this shows that she does not differentiate between „volume“ and „volume of a rotational body”, but between "volume" (fundamental term) and "rotational body" (concept to be defined). Even though Else starts with twice a „yes”, she does not support Maret's point of view, she only agrees in parts. She talks about volume as a concept $(, \ldots$ one that has hopefully been defined before”, line $72 \mathrm{f}$ ). This contradicts Maret's understanding of a fundamental term.

The statements clearly indicate that all pupils that were involved in the discussion are awake to the meaning of definition, theorem and fundamental term. In their descriptions they do, however, place emphasis on different things: Anne and Maret (lines 14 and 54f) stress the nature of stipulations as regards definitions, Else and Jochen point out that something new is added (lines 33 and 44). Both views are conformable. They disagree, however, concerning the question whether something new has been described or deduced. The answer depends on 
what is new and what is not new. This will then be discussed in the second part of the lesson, which is not further analyzed here.

\section{Relevance of a discursive teaching cul- ture}

In the pupils' contributions presented thus far, it is striking that reflection is often associated with the capability to linguistically differentiate exactly between things that were said, written and meant. In every day education, this is supported by a discursive teaching culture. It is vital to form a concept system in which the difference between signs and their meanings, between names and variables, the description of general regularities and special examples, are deliberately put at the pupils' disposal. The fact that reflection is naturally appreciated forms the precondition for realizing and appreciating reflection and is indispensable for learners and teachers.

„If pupils learn to express themselves appropriately, to reflect on language, if the teacher pays attention to a correct grammar, performances are increased." This statement by Klieme (2006), formulated as a result of the DESI-study, refers to German and English lessons, but the addition „And if all teachers support these aims, school as a whole will achieve better results" also imposes this responsibility on math teachers.

\section{References}

Boekaerts, M. (1996). Teaching Students SelfRegulated Learning: A Major Success in Applied Research. In J. Georgas et al. (Eds.), Contemporary Psychology in Europe, 245259. Seattle: Hogrefe \& Huber Publishers.

Bundesministerium für Bildung und Forschung [German Federal Ministry of education and research], BMBF (Ed.) (2001). TIMSS - Impulse für Schule und Unterricht [Impulses for School and Instruction]. Bonn.

Cohors-Fresenborg, E. (2001). Mathematik als Werkzeug zur Wissensrepräsentation: Das Osnabrücker Curriculum. [Mathematics as a tool for knowledge representation: The curriculum of Osnabrueck.] Der Mathematikunterricht 47(1), 5-13.

Cohors-Fresenborg, E. \& Kaune, C. (2003). Unterrichtsqualität: Die Rolle von Diskursivität für „guten“ gymnasialen Mathematikunter- richt. [Teaching quality: The role of discursivity for a "good“ mathematics education on grammar school level.] In Beiträge zum Mathematikunterricht 2003 (pp. 173-180). Hildesheim: Franzbecker.

Cohors-Fresenborg, E. \& Kaune, C. (2005a). Kategoriensystem für metakognitive Aktivitäten bei schrittweise kontrolliertem Argumentieren im Mathematikunterricht. [Category system for metacognitive activities in stepwisely controlled arguing in mathematics education.] Arbeitsbericht Nr. 44. Osnabrück: Forschungsinstitut für Mathematikdidaktik.

Cohors-Fresenborg, E. \& Kaune, C. (2005b). The Metaphor "Contracts to deal with Numbers" as a Structuring Tool in Algebra. Proceedings of CERME 4.

http://cerme4.crm.es/Papers\%20definitius/3/ Cohors_Kaune.pdf

De Corte, E. (1995). Fostering Cognitive Growth: A Perspective from Research on Mathematics Learning and Instruction. Educational Psychologist, 30(1), 37-46.

Dubinsky, E. (1991a). The Constructive Aspects of Reflective Abstraction in Advanced Mathematics. In L.P. Steffe (Ed.), Epistemological Foundations in Mathematical Experiences. New York: Springer.

Dubinsky, E. (1991b): Reflective Abstraction in Advanced Mathematical Thinking. In D. Tall (Ed.), Advanced Mathematical Thinking (pp. 95-123). Kluwer.

Flawell, J. (1979). Metacognition and cognitive monitoring. A new area of cognitivedevelopmental inquiry. American Psychologist 34, 906-911.

Herget, W. (1991). Mathematikunterricht - Wie geht es weiter? [Mathematics Education: How to proceed?] In H. Hischer (Ed.), Mathematikunterricht im Umbruch (pp. 139-148), Hildesheim: Franzbecker.

Kaune, C. (2001). Weiterentwicklung des Mathematikunterrichts: Die kognitions-orientierte Aufgabe ist mehr als „die etwas andere Aufgabe" [Advancements in mathematics education: The cognition-oriented problem is more than „a somewhat different problem“]. Der Mathematikunterricht 47(1), 35-46.

Kaune, C. (2005). Acht Jahre MUMAS - Eine Recherche in 1000 Unterrichtsszenen zum Variablenverständnis von Gymnasiasten. [Eight years of MUMAS: Research on 1000 scenes of lessons on variable comprehension in high school] In C. Kaune, I. Schwank \& J. Sjuts 
(Eds.), Mathematikdidaktik im Wissenschaftsgefüge. Zum Verstehen und Unterrichten mathematischen Denkens (pp. 131-151). Osnabrück: Forschungsinstitut für Mathematikdidaktik.

Kilpatrick, J. (1986). Reflection and Recursion. In M. Carss (Ed.), Proceedings of the Fifth International Congress on Mathematical Education (pp. 7-29). Boston: Birkhäuser.

Kind, R. (2004). Bericht der Sektion 8. In Niedersächsisches Kultusministerium (Ed.) [Report of Section 8 of the lower Saxony state ministry for education and cultural affairs], Ziele und Inhalte eines künftigen Mathematikunterrichts an Gymnasien, Fachgymnasien und Gesamtschulen (pp. 61-62).

Klieme, E. \& Helmke, A. (2005). „Oft sind die Lehrer zu ungeduldig“. [,Teachers are often too impatient.“] Die Zeit vom 9.3.2006, 75.

Konrad, K. (2005). Förderung und Analyse von selbstgesteuertem Lernen in kooperativen Lernumgebungen: Bedingungen, Prozesse und Bedeutung kognitiver sowie metakognitiver Strategien für den Erwerb und Transfer konzeptuellen Wissens [Promotion and analysis of self-directed learning in cooperative learning environments: Stipulations, processes and relevance of cognitive as well as metacognitive strategies for the acquisition and transfer of conceptual knowledge.]. Lengerich: Papst Science Publishers.

MNU: Deutscher Verein zur Förderung des mathematischen und naturwissenschaftlichen Unterrichts e.V. (1997). Forderungen an einen Mathematikunterricht der nichtgymnasialen Schulformen in der Sekundarstufe I.

[German association to enhance mathematics and scientific education (incorporated society). Requirements for mathematics education in non-grammar secondary schools.]

http://home.zugang.net/mnu-sachsen/sek1.htm

Schoenfeld, A.H. (1992). Learning to think mathematically: problem solving, metacognition and sense making in mathematics. In D. A. Groues (Ed.), Handbook of research on mathematics teaching and learning 334-370. New York: Macmillan.

Sjuts, J. (1999a). Mathematik als Werkzeug zur Wissensrepräsentation. Theoretische Einordnung, konzeptionelle Abgrenzung und interpretative Auswertung eines kognitions- und konstruktivismustheoretischen Mathematikunterrichts. [Mathematics as a tool for knowledge representation. Theoretical classification, conceptual differentiation and interpretative analysis of a cognitively and constructivistly theoretical mathematics education.] Osnabrück: Forschungsinstitut für Mathematikdidaktik.

Sjuts, J. (1999b). 'Metacognition in Mathematics Lessons'. In Developments in Mathematics Education in German-speaking Countries. Selected Papers from the Annual Conference on Didactics of Mathematics (pp. 76-87). Bern. http://webdoc.sub.gwdg.de/ebook/e/gdm/1999/ index.html

Wang, M. C., Haertel, G.. D. \& Walberg, H. J. (1993). Toward a Knowledge Base for School Learning. Review of Educational Research 63(3), 249-294.

\section{Author}

Christa Kaune, Apl. Prof. Dr.

Institute for Cognitive Mathematics

Faculty of Mathematics and Computer Science

University of Osnabrück

D-49069 Osnabrueck

Email: ckaune@mathematik.uni-osnabrueck.de 